\title{
Relationship between insulin resistance, coronary plaque, and clinical outcomes in patients with acute coronary syndromes: an analysis from the PROSPECT study
}

Serdar Farhan ${ }^{1 \dagger}$, Björn Redfors ${ }^{2,3,4 \dagger}$, Akiko Maehara ${ }^{2,3^{*}}$, Thomas McAndrew2 ${ }^{2}$ Ori Ben-Yehuda ${ }^{2,3}$, Bernard De Bruyne ${ }^{5}$, Roxana Mehran ${ }^{1,2}$, Birgit Vogel ${ }^{1}$, Gennaro Giustino ${ }^{1}$, Patrick W. Serruys $s^{6,7}$, Gary S. Mintz ${ }^{2}$ and Gregg W. Stone ${ }^{1,2}$

\begin{abstract}
Background: We investigated the association of insulin resistance (IR) with coronary plaque morphology and the risk of cardiovascular events in patients enrolled in the Providing Regional Observations to Study Predictors of Events in Coronary Tree (PROSPECT) study.

Methods: Patients with acute coronary syndromes (ACS) were divided based on DM status. Non-DM patients were further stratified according to homeostasis-model-assessment IR (HOMA-IR) index as insulin sensitive (IS; HOMA$I R \leq 2)$, likely-IR (LIR; $2<H O M A-I R<5)$, or diabetic-IR (DIR; HOMA-IR $\geq 5)$. Coronary plaque characteristics were investigated by intravascular ultrasound. The primary endpoint was major adverse cardiac events (MACE); a composite of cardiac death, cardiac arrest, myocardial infarction, and rehospitalization for unstable/progressive angina.
\end{abstract}

Results: Among non-diabetic patients, 109 patients (21.5\%) were categorized as LIR, and 65 patients (12.8\%) as DIR. Patients with DIR or DM had significantly higher rates of echolucent plaque compared with LIR and IS. In addition, DIR and DM were independently associated with increased risk of MACE compared with IS (adjusted hazard ratio [aHR] 2.29, 95\% confidence interval [CI] 1.22-4.29, $\mathrm{p}=0.01$ and aHR 2.12,95\% Cl 1.19-3.75, $\mathrm{p}=0.009$, respectively).

Conclusions: IR is common among patients with ACS. DM and advanced but not early stages of IR are independently associated with increased risk of adverse cardiovascular events.

Trial Registration ClinicalTrials.gov Identifier: NCT00180466.

Keywords: Acute coronary syndrome, Insulin resistance, Insulin, Glucose, Culprit and non-culprit lesion events

*Correspondence: amaehara@crf.org

†'Serdar Farhan and Björn Redfors contributed equally to this work

${ }^{2}$ Clinical Trials Center, Cardiovascular Research Foundation/ Columbia

University Medical Center, 1700 Broadway, 9th Floor, New York, NY 10019, USA

Full list of author information is available at the end of the article

\section{Background}

Diabetes mellitus (DM) is increasing in prevalence and is associated with an increased risk of adverse short and long-term cardiovascular events $[1,2]$. More than $50 \%$ of deaths among patients with DM are due to cardiovascular causes [3] despite tremendous development in medical treatment of DM. DM is caused by insulin resistance (IR) and/or defective insulin secretion [4], and IR is considered the earliest stage in the development of DM [4,

c) The Author(s) 2021. This article is licensed under a Creative Commons Attribution 4.0 International License, which permits use, sharing, adaptation, distribution and reproduction in any medium or format, as long as you give appropriate credit to the original author(s) and the source, provide a link to the Creative Commons licence, and indicate if changes were made. The images or other third party material in this article are included in the article's Creative Commons licence, unless indicated otherwise in a credit line to the material. If material is not included in the article's Creative Commons licence and your intended use is not permitted by statutory regulation or exceeds the permitted use, you will need to obtain permission directly from the copyright holder. To view a copy of this licence, visit http://creativeco mmons.org/licenses/by/4.0/. The Creative Commons Public Domain Dedication waiver (http://creativecommons.org/publicdomain/ zero/1.0/) applies to the data made available in this article, unless otherwise stated in a credit line to the data. 
5]. The extent of IR has been associated with increased risk of cardiovascular events in both non-diabetics as well as patients with DM [4, 5], and IR has been associated with an increased prevalence of lipid-rich coronary plaques and is associated with increased risk for cardiovascular events [6-8]. However, no prospective data on the association of IR with coronary plaque morphology in patients with acute coronary syndromes (ACS) are available, especially with respect to non-culprit coronary lesions. Therefore, we aimed to investigate the association between baseline IR and coronary plaque morphology and clinical outcomes in patients with ACS enrolled in the Providing Regional Observations to Study Predictors of Events in Coronary Tree (PROSPECT) study [9].

\section{Methods}

PROSPECT (NCT00180466) was an international study (United States and Europe) that investigated the natural history of coronary atherosclerosis in a population of patients admitted for ACS and treated successfully with percutaneous coronary intervention (PCI). The study design and main results have been published elsewhere [9]. In brief, 697 patients with ACS who were treated successfully with PCI for all lesions deemed responsible for the index event were enrolled. All patients underwent angiography as well as grayscale and virtual histology $(\mathrm{VH})$ intravascular ultrasound (IVUS) of the left main coronary artery as well as $6-8 \mathrm{~cm}$ of the proximal portion of each major epicardial coronary vessel after successful intervention of all culprit lesion(s). The present study includes patients in whom data on fasting insulin and glucose concentrations at baseline were available to determine IR. Patients were stratified according to their IR index, as defined by the homeostasis model assessment (HOMA-IR; fasting insulin $[\mathrm{mU} / \mathrm{mL}] \times$ fasting plasma glucose $[\mathrm{mg} / \mathrm{dL}] / 405)$. Patients without established DM were divided into the following groups based on their HOMA-IR values: Insulin sensitive (IS, HOMAIR $\leq 2$ ), likely-IR (LIR, $2<$ HOMA-IR $<5$ ), and diabetic-IR (DIR, HOMA-IR $\geq 5$ ) [10-12]. Patients with established DM were considered a separate group.

\section{Intravascular imaging}

Grayscale IVUS and VH-IVUS analyses were performed using QCU-CMS (Medis medical imaging systems bv, Leiden, the Netherlands), pcVH 2.1 (Volcano Corporation, San Diego, California) for contouring and data output, and proprietary software $(\mathrm{qVH}$, Cardiovascular Research Foundation, New York, NY, USA) for segmental quantitative and qualitative analysis [13, 14]. The external elastic membrane and lumen borders were detected approximately every $0.4 \mathrm{~mm}$ (depending on heart rate) and used to determine the external elastic membrane area, lumen area, and plaque area and burden (defined as $100 \times$ plaque area/external elastic membrane area). A non-culprit lesion was defined as $\geq 3$ consecutive frames with plaque burden $\geq 40 \%$. VH-IVUS allows the characterization of 4 different plaque components (red corresponds to necrotic core, green to fibrous tissue, light green to fibrofatty, and white to dense calcium). Based on its compositional traits, each lesion was classified as thincap fibroatheroma (TCFA), thick-cap fibroatheroma, fibrotic plaque, or fibrocalcific plaque [14, 15]. All IVUS frames were co-registered to the angiographic roadmap using fiduciary side branches for alignment.

\section{Endpoints}

The primary endpoint was the incidence of major adverse cardiac events (MACE), defined as cardiac death or arrest, myocardial infarction, or rehospitalization for unstable or progressive angina. The median follow up was 3.4 years. Endpoints were adjudicated by an independent events committee using original source documents and without knowledge of other patient data. Based on the follow-up angiography, recurrent MACE was adjudicated as occurring at initially treated (culprit), previously untreated (non-culprit) lesions, or indeterminate. On the basis of principal results [9], a high-risk lesion was defined as having 2 or more of the following: Plaque burden $\geq 70 \%$, minimum lumen area (MLA) $\leq 4.0$ $\mathrm{mm}^{2}$, or TCFA.

\section{Statistical analysis}

Baseline clinical and imaging data were stratified based on HOMA-IR and DM. Categorical variable are expressed as count and percentage and compared using the $x^{2}$ or Fisher exact test. Continuous variables are reported as median (interquartile range) and compared using Student's $t$-test or nonparametric Wilcoxon rank sum test. Outcomes are reported as Kaplan-Meier percentage and number of events and compared using the log-rank. Logistic regression analysis, adjusted for age and sex, was used to evaluate the relationship between the HOMA-IR groups and the probability of having IVUS any features of high-risk plaque (MLA $\leq 4 \mathrm{~mm}^{2}$, TCFA, and plaque burden $\geq 70 \%$ ). A multivariable Cox proportional hazards regression model was estimated the adjusted risk of 3-year MACE associated with HOMA-IR and DM. In regard to the risk of overall MACE, the following covariates were included in the model: The presence of $\geq 1$ lesion with a TCFA, presence of $\geq 1$ lesion with an MLA $\leq 4 \mathrm{~mm}^{2}$, age, sex, use of aspirin in the preceding 7 days, and a history of PCI. Due to a smaller number of events, the adjusted risks of culprit MACE and non-culprit MACE included the following reduced covariate set: Age, sex, use of aspirin in the preceding 
7 days, and a history of PCI [16]. A p value $<0.05$ was considered statistically significant. All statistical tests were performed using SAS version 9.2 (SAS Institute, Cary, NC, USA).

\section{Results}

\section{Baseline characteristics}

Out of 697 patients enrolled in the PROSPECT study, 507 patients had available data on HOMA-IR and 99 (19.5\%) had established DM. Among patients without DM, 109 patients (21.5\%) were categorized as LIR, and 65 patients $(12.8 \%)$ were categorized as DIR. The remaining 234 (46.2\%) patients had normal insulin sensitivity (IS). Patient clinical characteristics are presented in Table 1.
Patients with DIR and established DM had higher prevalence of metabolic risk factors compared with IS and LIR groups. Patients with DM were found to have the lowest glomerular filtration rate compared with the remaining 3 groups. With the exception of significantly elevated triglyceride concentration in patients with DM compared with the other groups, the baseline lipid profile was comparable across the groups.

\section{IVUS characteristics of non-culprit lesion}

IVUS parameters stratified according to HOMA-IR status are presented in Table 2. On grayscale IVUS evaluation, patients with DIR had significantly higher total lesion length compared with the established DM, LIR,

Table 1 Baseline and clinical characteristics

\begin{tabular}{|c|c|c|c|c|c|}
\hline & Insulin sensitive $(n=234)$ & $\begin{array}{l}\text { Likely insulin } \\
\text { resistance } \\
(n=109)\end{array}$ & $\begin{array}{l}\text { Diabetic insulin } \\
\text { resistance } \\
(n=65)\end{array}$ & Diabetes mellitus $(n=99)$ & $p$ value \\
\hline Age, years & $59.3(51.5-67.7)$ & $57.2(49.2-65.0)$ & $57.6(49.6-65.5)$ & $60.8(54.5-69.9)$ & 0.056 \\
\hline Male & $76.5(179 / 234)$ & $78.9(86 / 109)$ & $84.6(55 / 65)$ & $69.7(69 / 99)$ & 0.15 \\
\hline Waist circumference, $\mathrm{cm}$ & $97.0(89.0-103.0)$ & $104.1(96.0-113.0)$ & $106.7(96.5-115.0)$ & $104.1(94.0-114.3)$ & $<0.0001$ \\
\hline Body mass index, $\mathrm{kg} / \mathrm{m}^{2}$ & $26.9(24.5-29.3)$ & $29.6(26.5-33.5)$ & $30.0(27.1-35.5)$ & $29.4(26.3-32.8)$ & $<0.0001$ \\
\hline Systolic BP, mm Hg & $130(112-144)$ & $130(119-140)$ & $133(120-143)$ & $130(115-146)$ & 0.50 \\
\hline Diastolic BP, mm Hg & $73(63-81)$ & $75(70-82)$ & $74(68-84)$ & $70(67-85)$ & 0.19 \\
\hline Prior myocardial infarction & $11.7(27 / 231)$ & $8.3(9 / 108)$ & $10.8(7 / 65)$ & $12.1(12 / 99)$ & 0.79 \\
\hline Family history of CAD & $39.4(82 / 208)$ & $48.0(47 / 98)$ & $56.1(32 / 57)$ & $34.5(29 / 84)$ & 0.04 \\
\hline Hypertension requiring medication & $42.0(97 / 231)$ & $46.8(51 / 109)$ & $46.2(30 / 65)$ & $65.3(64 / 98)$ & 0.002 \\
\hline $\begin{array}{l}\text { Hypercholesterolemia requiring } \\
\text { medication }\end{array}$ & $44.3(94 / 212)$ & $33.3(33 / 99)$ & $39.3(24 / 61)$ & $60.0(57 / 95)$ & 0.002 \\
\hline Current smoking & $50.4(117 / 232)$ & $41.5(44 / 106)$ & $40.0(26 / 65)$ & $40.2(39 / 97)$ & 0.18 \\
\hline \multicolumn{6}{|l|}{ Clinical presentation } \\
\hline STEMI & $26.1(61 / 234)$ & $27.5(30 / 109)$ & $26.2(17 / 65)$ & $26.3(26 / 99)$ & 0.99 \\
\hline Non-STEMI & $67.1(157 / 234)$ & $69.7(76 / 109)$ & $73.8(48 / 65)$ & $72.7(72 / 99)$ & 0.64 \\
\hline Unstable angina & $6.8(16 / 234)$ & $2.8(3 / 109)$ & $0.0(0 / 65)$ & $1.0(1 / 99)$ & 0.01 \\
\hline \multicolumn{6}{|c|}{ Laboratory parameters during index hospitalization } \\
\hline $\mathrm{eGFR}, \mathrm{mL} / \mathrm{min}$ & $93.9(75.2-116.8)$ & $104.7(78.5-140.6)$ & $109.6(79.7-138.0)$ & $97.8(68.7-127.5)$ & 0.02 \\
\hline Total cholesterol, mg/dL & $170.0(148-195)$ & $172.0(153.8-192.3)$ & $171.0(153.8-197)$ & $161.5(140.5-198.5)$ & 0.66 \\
\hline $\mathrm{HDL}, \mathrm{mg} / \mathrm{dL}$ & $38.6(34-46)$ & $38.6(32-41)$ & $38.6(33-44)$ & $39.0(32-49)$ & 0.13 \\
\hline $\mathrm{LDL}, \mathrm{mg} / \mathrm{dL}$ & $101.2(81.1-129.2)$ & $104.4(78.4-125.6)$ & $109.0(83-149.6)$ & $93.6(67-121.0)$ & 0.12 \\
\hline Triglycerides, mg/dL & $118.0(88.6-163.0)$ & $128.0(88.6-177.1)$ & $140.5(101.5-179.0)$ & $145.5(97.0-206.0)$ & 0.02 \\
\hline Fasting glucose, mg/dL & $92(87-100)$ & $107(96-115)$ & $120(106-139)$ & $123(103-160)$ & $<0.0001$ \\
\hline Fasting insulin, $\mu \mathrm{U} / \mathrm{L}$ & $6.0(4.0-8.0)$ & $13.0(11.0-16.0)$ & $31.5(24.0-55.0)$ & $11.0(6.0-22.0)$ & $<0.0001$ \\
\hline $\mathrm{HbA} 1 \mathrm{c}, \%$ & $5.6(5.2-6.0)$ & $5.7(5.3-6.0)$ & $5.7(5.3-5.9)$ & $6.6(6.2-7.5)$ & $<0.0001$ \\
\hline C-reactive protein, $\mathrm{mg} / \mathrm{dL}$ & $6.90(2.10-17.00)$ & $12.55(3.70-27.65)$ & $8.65(3.40-24.00)$ & $6.95(2.60-21.85)$ & 0.005 \\
\hline \multicolumn{6}{|l|}{ Medication at discharge } \\
\hline Lipid lowering drug & $88.5(207 / 234)$ & $90.8(99 / 109)$ & $90.8(59 / 65)$ & $86.9(86 / 99)$ & 0.78 \\
\hline Aspirin & $98.3(230 / 234)$ & $97.2(106 / 109)$ & $96.9(63 / 65)$ & $98.0(97 / 99)$ & 0.88 \\
\hline Thienopyridine & $98.3(230 / 234)$ & $100.0(109 / 109)$ & $98.5(64 / 65)$ & $97.0(96 / 99)$ & 0.37 \\
\hline Beta blocker & $91.5(214 / 234)$ & $89.9(98 / 109)$ & $93.8(61 / 65)$ & $89.9(89 / 99)$ & 0.80 \\
\hline
\end{tabular}

Values are median (interquartile range) or $\%(\mathrm{n} / \mathrm{N})$. BP, blood pressure; CAD, coronary artery disease; eGFR, estimated glomerular filtration rate; HbA1c, glycosylated hemoglobin; HDL, high-density lipoprotein; LDL, low-density lipoprotein; STEMI, ST-segment elevation myocardial infarction 
Table 2 Patient level intravascular ultrasound features of non-culprit lesions

\begin{tabular}{|c|c|c|c|c|c|}
\hline & Insulin sensitive $(n=234)$ & $\begin{array}{l}\text { Likely insulin } \\
\text { resistance } \\
(n=109)\end{array}$ & $\begin{array}{l}\text { Diabetic insulin } \\
\text { resistance } \\
(n=65)\end{array}$ & Diabetes mellitus $(n=99)$ & $\mathrm{p}$ value \\
\hline \multicolumn{6}{|l|}{ Grayscale intravascular ultrasound } \\
\hline Number of lesions & $5(3-6)$ & $5(4-6)$ & $6(4-7)$ & $5(4-6)$ & 0.05 \\
\hline$\geq 1$ echolucent plaque & $14.5(32 / 221)$ & $8.7(9 / 103)$ & $23.8(15 / 63)$ & $20.2(19 / 94)$ & 0.03 \\
\hline$\geq 1$ plaque rupture & $12.2(27 / 221)$ & $20.4(21 / 103)$ & $17.5(11 / 63)$ & $11.7(11 / 94)$ & 0.18 \\
\hline Total lesion length, mm & $69.3(40.0-103.0)$ & $72.4(46.1-96.8)$ & $94.5(61.1-115.9)$ & $66.1(45.6-95.0)$ & 0.02 \\
\hline Plaque volume, $\%$ & $49.6(47.0-52.3)$ & $48.8(46.1-51.2)$ & $49.0(46.6-52.5)$ & $49.6(46.8-52.3)$ & 0.27 \\
\hline Average EEM CSA, $\mathrm{mm}^{3} / \mathrm{mm}$ & $15.8(13.8-18.4)$ & $16.3(14.6-19.5)$ & $17.3(14.3-19.2)$ & $16.5(14.2-18.4)$ & 0.11 \\
\hline Average luminal $\mathrm{CSA}, \mathrm{mm}^{3} / \mathrm{mm}$ & $8.0(6.8-9.2)$ & $8.6(7.1-10.1)$ & $8.7(7.0-9.9)$ & $8.0(7.0-9.4)$ & 0.04 \\
\hline \multicolumn{6}{|l|}{ VH-intravascular ultrasound } \\
\hline Average necrotic core CSA, $\mathrm{mm}^{3} / \mathrm{mm}$ & $0.54(0.26-0.82)$ & $0.55(0.34-0.89)$ & $0.49(0.34-0.73)$ & $0.50(0.31-0.78)$ & 0.90 \\
\hline Average dense calcium CSA, $\mathrm{mm}^{3} / \mathrm{mm}$ & $0.24(0.11-0.42)$ & $0.21(0.14-0.40)$ & $0.18(0.11-0.34)$ & $0.24(0.12-0.41)$ & 0.75 \\
\hline Average fibrous tissue CSA, $\mathrm{mm}^{3} / \mathrm{mm}$ & $2.48(1.89-3.14)$ & $2.64(1.99-3.44)$ & $2.79(2.15-3.62)$ & $2.73(2.10-3.37)$ & 0.10 \\
\hline Average fibrofatty CSA, $\mathrm{mm}^{3} / \mathrm{mm}$ & $0.80(0.49-1.20)$ & $0.82(0.54-1.11)$ & $0.95(0.56-1.59)$ & $0.92(0.57-1.40)$ & 0.12 \\
\hline $\begin{array}{l}\text { Total number of VH-TCFA lesions per } \\
\text { patients }\end{array}$ & $1.0(0.0-2.0)$ & $1.0(0.0-2.0)$ & $1.0(0.0-1.0)$ & $1.0(0.0,1.5)$ & 0.43 \\
\hline \multicolumn{6}{|l|}{ High-risk plaque characteristics } \\
\hline$\geq 1$ lesion with $\mathrm{MLA} \leq 4 \mathrm{~mm}^{2}$ & $57.9(128 / 221)$ & $46.6(48 / 103)$ & $55.6(35 / 63)$ & $60.6(57 / 94)$ & 0.18 \\
\hline$\geq 1$ lesion with plaque burden $\geq 70 \%$ & $29.9(66 / 221)$ & $33.0(34 / 103)$ & $39.7(25 / 63)$ & $35.1(33 / 94)$ & 0.49 \\
\hline$\geq 1 \mathrm{VH}-\mathrm{TCFA}$ & $54.2(110 / 203)$ & $63.8(60 / 94)$ & $53.3(32 / 60)$ & $55.7(49 / 88)$ & 0.43 \\
\hline
\end{tabular}

Values are median (interquartile range) or \% (n/N). CSA, cross-sectional area; EEM, external elastic membrane; MLA, minimal lumen area; TCFA, thin-cap fibroatheroma

and IS groups. Furthermore, patients with DIR and established DM had a higher prevalence of echolucent plaques compared to patients with IS and LIR. There was no difference in the proportion of patients with $M L A \leq 4 \mathrm{~mm}^{2}$ or plaque burden $\geq 70 \%$ among the HOMA-IR groups. On VH-IVUS analysis there were no significant differences in volumetric parameters or lesion phenotypes across the 4 groups.

\section{Association between HOMA-IR and IVUS features of high-risk plaque}

HOMA-IR was not associated with the high-risk plaque features including (i) presence of $\geq 1$ TCFA (LIR versus IS: Odds ratio [OR] 1.44, 95\% confidence interval [CI] $0.87-2.39, \mathrm{p}=0.14$; DIR versus IS: OR $0.94,95 \% \mathrm{CI} 0.53-$ $1.68, \mathrm{p}=0.45$; DM versus IS: OR $1.08,95 \%$ CI $0.65-1.79$, $\mathrm{p}=0.94$ ); (ii) presence of $\geq 1$ lesion with $\mathrm{MLA}<4 \mathrm{~mm}^{2}$ (LIR versus IS: OR 0.64, 95\% CI 0.39-1.03, $\mathrm{p}=0.051$; DIR versus IS: OR $0.95,95 \% \mathrm{CI} 0.54-1.67, \mathrm{p}=0.80$; $\mathrm{DM}$ versus IS: OR $1.08,95 \%$ CI $0.65-1.77, \mathrm{p}=0.32$ ) and (iii) plaque burden $\geq 70 \%$ (LIR versus IS: OR 1.19, 95\% CI 0.72-1.98, $\mathrm{p}=0.83$; DIR versus IS: OR $1.56,95 \%$ CI $0.87-2.80$, $\mathrm{p}=0.28$; and DM versus IS: OR $1.28,95 \%$ CI $0.76-2.14$, $\mathrm{p}=0.87$ ). There were no differences in the prevalence of TCFA according to HOMA-IR status among patients non-culprit MACE $(p=0.38)$ those without non-culprit $\operatorname{MACE}(\mathrm{p}=0.77)$.

\section{Clinical outcomes}

Table 3 presents 3-year clinical endpoints stratified according to HOMA-IR. Patients with DIR and DM had significantly higher crude MACE rates compared with LIR and IS (29.9\%, 27.7\%, 17.6\%, and 15.5\%, respectively, $\mathrm{p}=0.01$ ), which was mainly driven by higher rates of revascularization and myocardial infarction in patients with DIR and DM (Table 3 and Fig. 1). The crude MACE rates related to the culprit lesion were also higher in DIR and DM than LIR and IS patients $(20.4 \%, 17.3 \%, 13.8 \%$, and $8 \%$, respectively, $\mathrm{p}=0.02$, Fig. 1 ). Definite and probable ST occurred only in patients with DIR and DM (4.7\% and 3.4\%, respectively, versus $0 \%$ in the LIR and IS groups, $\mathrm{p}=0.004)$. Compared with IS, the adjusted risk of MACE was significantly higher for DIR and DM but not LIR (Fig. 2a). Similarly, HOMA-IR $\geq 5$ was independently predictive of culprit MACE and a trend for nonculprit MACE (Fig. 2b and c).

\section{Discussion}

The key findings of the present analysis from the PROSPECT study are (i) the prevalence of DIR is high among non-DM patients with ACS, (ii) both DM and DIR estimated using the HOMA index are associated with more echolucent plaques compared with patients with normal or moderate IR, and (iii) both DIR and DM were predictive of ischemic events after ACS; DIR predicted MACE 
Table 3 Cumulative rates of major adverse cardiac events

\begin{tabular}{|c|c|c|c|c|c|}
\hline & $\begin{array}{l}\text { Insulin } \\
\text { sensitive } \\
(n=234)\end{array}$ & $\begin{array}{l}\text { Likely insulin } \\
\text { resistance } \\
(n=109)\end{array}$ & $\begin{array}{l}\text { Diabetic insulin } \\
\text { resistance }(n=65)\end{array}$ & $\begin{array}{l}\text { Diabetes } \\
\text { mellitus } \\
(n=99)\end{array}$ & $\mathrm{p}$ value \\
\hline \multicolumn{6}{|l|}{ Overall } \\
\hline Major adverse cardiac events ${ }^{* a}$ & $15.5(33)$ & $17.6(18)$ & $29.9(19)$ & $27.7(24)$ & 0.01 \\
\hline Cardiac death & $2.4(5)$ & $0(0)$ & $3.2(2)$ & $1.2(1)$ & 0.38 \\
\hline Myocardial infarction ${ }^{b}$ & $0.9(2)$ & $1.0(1)$ & $5.0(3)$ & $7.2(6)$ & 0.01 \\
\hline Cardiac death, cardiac arrest, or myocardial infarction & $2.9(6)$ & $1.0(1)$ & $8.1(5)$ & $8.3(7)$ & 0.03 \\
\hline Rehospitalization due to unstable or increasing angina & $14.1(30)$ & $16.6(17)$ & $25.3(16)$ & $22.9(20)$ & 0.09 \\
\hline Revascularization $(\mathrm{PCl} \text { or } \mathrm{CABG})^{c}$ & $10.9(23)$ & $14.7(15)$ & $27.1(17)$ & $23.5(20)$ & 0.003 \\
\hline Stent thrombosis ${ }^{\mathrm{d}}$ & $2.0(4)$ & $0(0)$ & $4.7(3)$ & $4.6(4)$ & 0.11 \\
\hline \multicolumn{6}{|l|}{ Culprit lesion } \\
\hline Major adverse cardiac events*a & $8.0(17)$ & $13.8(14)$ & $20.4(13)$ & $17.3(15)$ & 0.02 \\
\hline Cardiac death & $0(0)$ & $0(0)$ & $1.6(1)$ & $0(0)$ & 0.09 \\
\hline Myocardial infarction ${ }^{e}$ & $0.5(1)$ & $0(0)$ & $1.6(1)$ & $4.6(4)$ & 0.02 \\
\hline Cardiac death, cardiac arrest, or myocardial infarction & $0.5(1)$ & $0(0)$ & $3.1(2)$ & $4.6(4)$ & 0.02 \\
\hline Rehospitalization due to unstable or increasing angina & $8.0(17)$ & $13.8(14)$ & $19.1(12)$ & $13.8(12)$ & 0.07 \\
\hline Revascularization (PCl or $\mathrm{CABG})^{*}$ & $6.2(13)$ & $10.8(11)$ & $17.5(11)$ & $15.2(13)$ & 0.02 \\
\hline Stent thrombosis ${ }^{c, d}$ & $0.0(0)$ & $0.0(0)$ & $4.7(3)$ & $3.4(3)$ & 0.004 \\
\hline \multicolumn{6}{|l|}{ Non-culprit lesion } \\
\hline Major adverse cardiac events ${ }^{\mathrm{a}}$ & $9.2(19)$ & $8.9(9)$ & $19.2(12)$ & $16.5(14)$ & 0.057 \\
\hline Cardiac death & $0(0)$ & $0(0)$ & $0(0)$ & $0(0)$ & - \\
\hline Myocardial infarction & $0.0(0)$ & $1.0(1)$ & $3.4(2)$ & $1.4(1)$ & 0.13 \\
\hline Rehospitalization due to unstable or increasing angina & $9.2(19)$ & $7.9(8)$ & $17.5(11)$ & $15.1(13)$ & 0.10 \\
\hline Revascularization (PCl or $\mathrm{CABG})^{\mathrm{f}}$ & $7.8(16)$ & $7.9(8)$ & $19.2(12)$ & $14.1(12)$ & 0.03 \\
\hline \multicolumn{6}{|l|}{ Indeterminate events } \\
\hline Major adverse cardiac events ${ }^{\mathrm{a}}$ & $2.9(6)$ & $1.0(1)$ & $1.7(1)$ & $4.7(4)$ & 0.44 \\
\hline Cardiac death & $2.4(5)$ & $0(0)$ & $1.7(1)$ & $1.2(1)$ & 0.46 \\
\hline Myocardial infarction & $0.5(1)$ & $0(0)$ & $0(0)$ & $1.1(1)$ & 0.62 \\
\hline Rehospitalization due to unstable or increasing angina & $0.5(1)$ & $1.0(1)$ & $0(0)$ & $2.4(2)$ & 0.39 \\
\hline Revascularization $(\mathrm{PCl} \text { or } \mathrm{CABG})^{f}$ & $0(0)$ & $0(0)$ & $0(0)$ & $0(0)$ & - \\
\hline
\end{tabular}

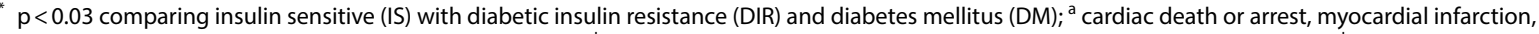
rehospitalization for unstable angina, or increasing angina; ${ }^{b} \mathrm{p}<0.05$ comparing IS and $D M ;{ }^{c} p<0.005$ comparing IS with DIR and DM; ${ }^{d}$ definite or possible per Academic Research Consortium definition; ${ }^{\mathrm{e}} \mathrm{p}=0.01$ comparing IS with $\mathrm{DM} ;{ }^{\mathrm{f}} \mathrm{p}<0.005$ comparing IS with $\mathrm{DIR}$. CABG, coronary artery bypass grafting; $\mathrm{PCI}$, percutaneous coronary intervention

in culprit as well as non-culprit lesions and DM predicted culprit lesion MACE in this analysis. Thus, among patients with ACS, not only patients with DM but also DIR constitute high-risk subgroups.

\section{IR and the development/progression of atherosclerosis:}

DM is associated with accelerated progression of atherosclerosis and cardiovascular disease [17] and is a widespread disorder that develops gradually from early forms of glucometabolic disturbances to clinically manifest DM [18]. While the pathophysiology of atherosclerotic plaque development is multifactorial and impacted by obesity, lipoprotein metabolism, hypeglycemia and inflammation [19-23], even early stages of impaired glucometabolism such as IR in which fasting and postprandial glucose levels remain within normal limits $[4,18]$, may be associated with some of the underlying mechanisms. With deterioration of insulin sensitivity, the pancreatic $ß$-cells respond to the elevated glucose concentration by increasing insulin production. Hyperinsulinemia, in turn, has been linked to atherosclerosis progression [24]. IR has a pro-inflammatory and pro-coagulatory effect and is associated with endothelial dysfunction [20, 25]. Supporting evidence for a complex interplay of many different factors resulting from metabolic disturbances as the basis of atherosclerosis progression was derived from a study in patients with stable coronary artery disease [26]. Low PCSK9 plasma levels were associated with a particular metabolic phenotype (low HDL cholesterol, the metabolic syndrome, obesity, insulin resistance and diabetes) 
a

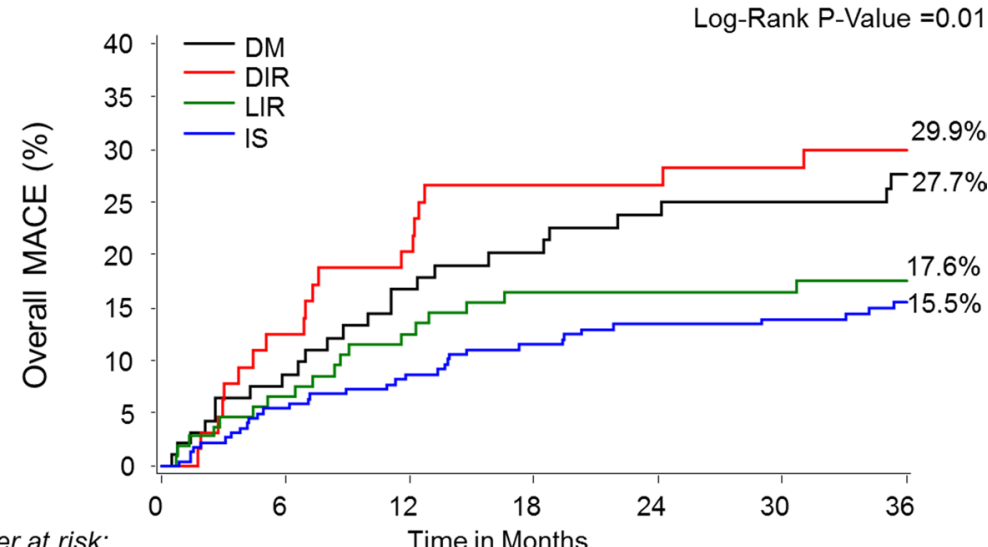

Number at risk:

Time in Months

$\begin{array}{lrrrrrrr}\text { DM } & 99 & 80 & 72 & 68 & 63 & 60 & 34 \\ \text { DIS } & 65 & 56 & 51 & 46 & 46 & 43 & 26 \\ \text { LIR } & 109 & 96 & 87 & 82 & 79 & 76 & 52 \\ \text { IS } & 234 & 205 & 196 & 186 & 176 & 171 & 101\end{array}$

b

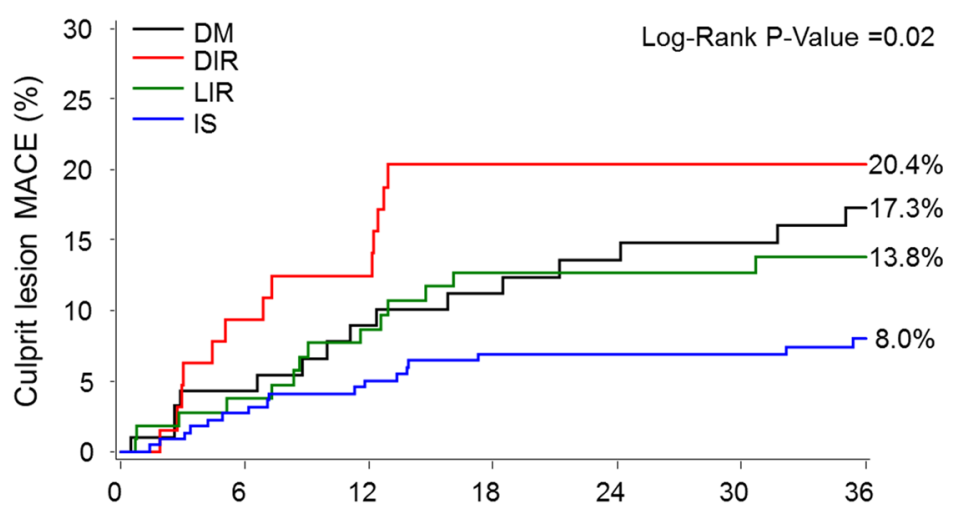

Number at risk:

$\begin{array}{lrl}\text { DM } & 99 \\ \text { DIS } & 65 \\ \text { LIR } & 109 \\ \text { IS } & 234\end{array}$

Time in Months

c

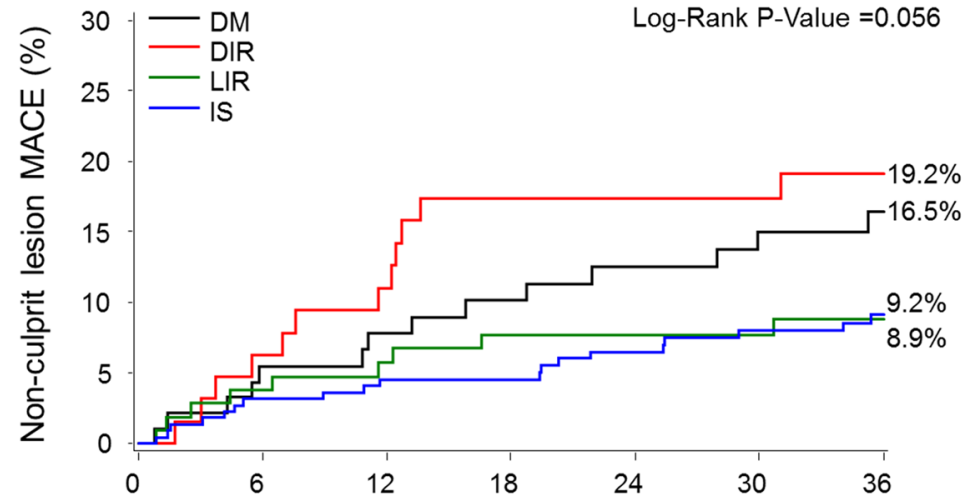

Number at risk:

$\begin{array}{rrrrrrr}99 & 84 & 79 & 76 & 71 & 68 & 40 \\ 65 & 58 & 56 & 50 & 50 & 47 & 30 \\ 09 & 99 & 91 & 86 & 83 & 80 & 56 \\ 34 & 211 & 204 & 194 & 188 & 183 & 109\end{array}$




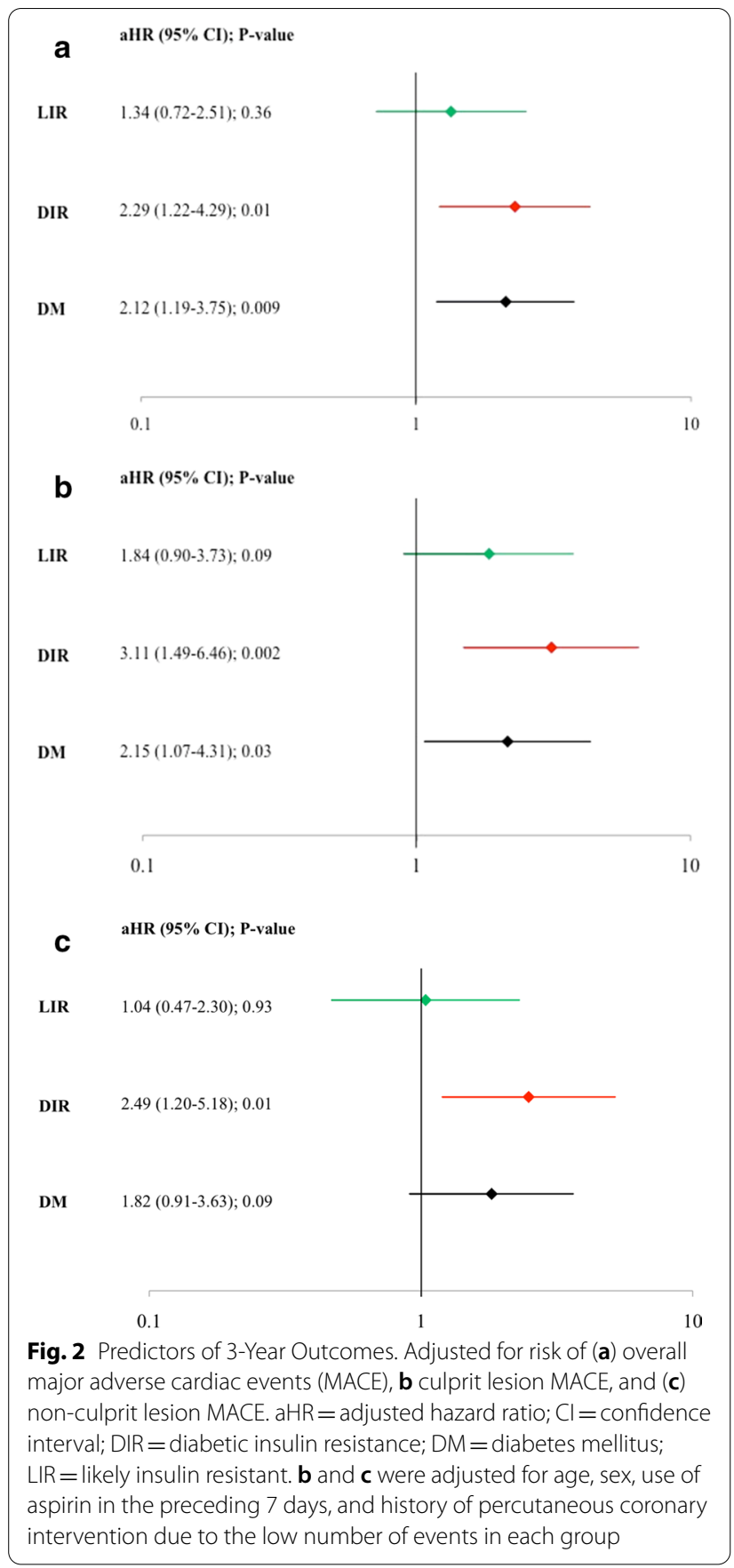

[26] and a higher computed tomography angiography score which was computed by combining the extent, severity, composition, and location of atherosclerotic plaques [27]. In the present study, not only patients with DM but also those with DIR had higher levels of insulin, and fasting glucose, waist circumference, BMI and more proatherogenic lipid profile. Both hyperinsulinemia and IR have been shown to be associated with incident CAD, independent of traditional cardiovascular risk factors [28-30]. Furthermore, IR was found to be independently associated de-novo ischemic heart disease and new PCI even in subjects with normal glucose tolerance [31]. Therefore, it is not surprising, however, important to acknowledge that the proportion of patients with any level of glucometabolic disturbance in our ACS population was high.

Studies in manifest diabetes have found an association between an increase in HbA1c and HOMA-IR and coronary plaque progression [27]. In addition, increased duration of DM combined with higher HbA1c levels In obesity, acute hyperglycemia, and proatherogenic lipid profile were linked to progression of atherosclerosis and cardiovascular outcomes [21, 22, 26, 31, 32]. These patients had higher prevalence of more advanced atherosclerotic plaque features compared with patients with LIR and IS.

\section{IR and plaque vulnerability:}

Despite extensive investigation on factors leading to plaque instability the mechanisms resulting in the development of vulnerable plaques have not been fully elucidated. One study using optical coherence tomography found an association of longer duration of DM and higher HbA1c with increased prevalence of lipid-rich plaques, TCFA, and plaque ruptures of culprit lesions in patients with AMI [32]. Another recent study suggested that an impairment of the glycocalyx and lower levels of syndecan-1 may be involved in the development of vulnerable plaques [19]. Other data suggested that plaque vulnerability is related to abnormal abdominal fat distribution, rather than with the visceral or subcutaneous fat amount alone in patients with ACS [22]. Recent investigations have also linked IR with specific IVUS features of coronary plaque vulnerability [6, 7, 33]. Iguchi et al. [7] investigated 155 consecutive patients with stable CAD and ACS using optical coherence tomography and found a strong correlation between TCFA and IR. Additionally, coronary plaques from patients in the highest tertile of IR showed higher lipid content compared with middle and lower IR tertiles [7]. In a study with a similar design but using IVUS as imaging tool, Amano et al. [6] found higher rates of lipid-rich plaque in patients with a higher degree of IR compared to those with a lower degree of IR. Mitsuhashi et al. [33] were able to show that higher insulin secretion was associated with coronary plaques with lipid content. In the present study, patients with DIR and DM showed significantly higher rates of echolucent plaques compared with LIR and IS, however, there were no differences with respect to necrotic core, calcium content, fibrous tissue, and fibrofatty tissue among the investigated groups. While echolucent plaque indicates early stages of atherosclerosis including either lipid 
pool in pathological intimal thickening or early necrotic core, the presence of TCFA specifies more advanced atherosclerosis [34]. Unlike previous investigations we were not able to show a correlation between TCFA and IR status. There are several possible explanations for these discrepant results. First, we investigated patients with ACS and performed IVUS analysis of the non-culprit vessels after successful PCI of the culprit lesion. Iguchi et al. [7] and Amano et al. [6] studied a wide spectrum of CAD patients including stable CAD and ACS, and only investigated culprit lesions by intracoronary imaging. Second, although IVUS was performed in all major epicardial vessels, only the first 6 to $8 \mathrm{~cm}$ were investigated in PROSPECT. Previous studies have shown that the distal portions of the coronary arteries are particularly often diseased in patients with DM $[35,36]$, which may also be the case in patients with DIR. Finally, the PROSPECT study compared with previous investigations was a prospective, multicenter study utilizing blinded core lab IVUS analysis and independent outcome data adjudication.

\section{Association of IR and outcomes after ACS}

The present PROSPECT substudy demonstrated an independent association between markedly elevated HOMA-IR with future cardiovascular events. The DIRassociated risk of MACE observed in PROSPECT is also consistent with the literature, as a recent meta-analysis showed that HOMA-IR $\geq 5$ was an independent correlate of cardiovascular events in patients without DM [37]. The observation that the adjusted risk of MACE was increased in patients with DIR but not LIR is consistent with previous research, which showed that earlier stages of hyperglycemia have a more favorable outcome compared with advanced stages of pre-DM $[38,39]$. The significantly higher risk of definite/probable ST in DIR and DM compared to IS and LIR patients is in keeping with the pro-coagulatory effects of.advanced glucometabolic disturbances discussed above. However, this finding should be interpreted with caution due to the small sample size of the present study and the lack of statistical power with regards to the endpoint of ST. As such, these findings are encouraging and imply that greater attention and more comprehensive screening for subclinical glucometabolic disturbances and earlier initiation of therapy may reduce the risk of adverse cardiovascular events for patients with IR $[21,40]$. Indeed, earlier trials showed a reduction in the conversion rate from pre-DM to overt DM through lifestyle modification and early initiation of medical therapy [41]. Interestingly, in the present study, DIR was associated with both culprit and non-culprit lesion MACE while DM was only associated with culprit lesion MACE. Other than a play of chance one can hypothesize whether antihypeglycemic treatment in the DM but not in DIR group has mediated these findings. These observations are particularly important considering the high prevalence of IR among patients with ACS, with a recently reported incidence of IR of 55\% among non-diabetic patients presenting with ST-segment elevation myocardial infarction [42], and with HOMA-IR $\geq 2$ found in $42.6 \%$ of patients without established DM in PROSPECT.

\section{Limitations}

This analysis from the PROSPECT study has several limitations. First, as this study was a post hoc analysis of a prospective study, our findings should be interpreted as hypothesis generating rather than conclusive. Second, we used HOMA-IR as a surrogate marker of IR and not by using the gold standard method hyperinsulinemiceuglycemic clamp; however, HOMA-IR has been shown to be comparable to hyperinsulinemic-euglycemic clamp in patients with ACS [43]. Also no oral glucose tolerance test was performed in those patients not known as diabetics. Thereby the true rate of DM might be underestimated in our study. Third, as we investigated patients with ACS, we cannot rule out the influence of stress hormones, eg. catecholamines and corticosteroids, on our results [42, 44]; however, glucose tolerance has been shown to remain stable within 3 months after myocardial infarction [45]. Forth, since the PROSPECT study was conducted before novel antiplatelet drugs were commercially available; our analysis cannot be directly applied to patients who received novel antiplatelet drugs.

\section{Conclusions}

IR is highly prevalent among patients with ACS. DM and advanced but not early stages of IR are independently associated with an increased risk of adverse cardiovascular events in patients after ACS. Further research is warranted to investigate the role of IR in the development and progression of coronary atherosclerosis, and the potential for therapeutic interventions specifically targeting IR.

\section{Abbreviations \\ DM: Diabetes mellitus; IR: Insulin resistance; ACS: Acute coronary syndromes; PCI: Percutaneous coronary intervention; VH: Virtual histology; IVUS: Intravas- cular ultrasound; HOMA-IR: Homeostasis model assessment; TCFA: Thin-cap fibroatheroma; MACE: Major adverse cardiovascular events; MLA: Minimum lumen area; DIR: Diabetic insulin resistance; LIR: Likely insulin resistance; IS: Insulin sensitivity.}

\section{Acknowledgements \\ None.}

Authors' contributions

SF and BR wrote manuscript, researched data, statistical analysis; AM drafted manuscript, data interpretation, image analysis; TMA statistical analysis; OBJ, 
BD, RM, PS, GM researched data, image analysis, patient recruitment, edited manuscript an contributed to discussion; BV, GG researched data, edited manuscript; GS PI of the study, researched data, drafted and edited manuscript and statistical analysis. All authors read and approved the final manuscript.

\section{Funding}

PROSPECT was supported by Abbott Vascular and by Volcano.

\section{Availability of data and materials}

The data, analytic methods, and study materials are proprietary to the sponsor and at this time are not available to non-study participants.

\section{Ethics approval and consent to participate}

All patients provided written informed consent. The study was approved by the institutional review board at each participating center.

\section{Consent for publication}

Not applicable.

\section{Competing interests}

Akiko Maehara: Grant support from Abbott Vascular and Boston Scientific, consultant for Conavi Medical Inc. Bernard De Bruyne: Institutional grant support from Abbott, Boston Scientific, and Biotronik AG; institutional consulting fees from Abbott, Opsens, and Boston Scientific. Roxana Mehran: Institutional Grant Support (funding to the institution)—AstraZeneca, Bayer, Beth Israel Deaconess, BMS, CSL Behring, DSI, BSC, Novartis Pharmaceuticals, OrbusNeich; Consulting Fees-Medscape, Regeneron Pharmaceuticals (no fee, Sanofi, Abbott Laboratories (personal fees for speaking engagements; consultant (paid to the institution), Abiomed and The Medicines Company (consultant spouse); Scientific Advisory Board/Advisory Board—PLx Opco Inc./PLx Pharma Inc. (scientific advisory board), Bristol Myers Squibb (advisory board; funding to the institution); Equity < 1\%-Claret Medical, Elixir Medical; Executive Committee (paid to the institution)—Janssen Pharmaceuticals; DSMB Membership - Watermark Research Partners. Patrick W. Serruys: Consultant - Abbott, Biosensors, Medtronic, Micell Technologies, SINOMED, Philips/Volcano, Xeltis, HeartFlow. Gary S. Mintz: Honoraria—Boston Scientific, Philips, Terumo, and Medtronic. The rest of the authors: none.

\section{Author details}

${ }^{1}$ Icahn School of Medicine At Mount Sinai, The Zena and Michael A. Wiener Cardiovascular Institute, New York, NY, USA. ${ }^{2}$ Clinical Trials Center, Cardiovascular Research Foundation/Columbia University Medical Center, 1700 Broadway, 9th Floor, New York, NY 10019, USA. ${ }^{3}$ NewYork-Presbyterian Hospital/ Columbia University Irving Medical Center, New York, NY, USA. ${ }^{4}$ Department of Cardiology, Sahlgrenska University Hospital, Gothenburg, Sweden. ${ }^{5}$ The Cardiovascular Center, OLV Hospital, Aalst, Belgium. ${ }^{6}$ Department of Cardiology, NUIG, National University of Ireland, Galway, Ireland. ${ }^{7}$ Imperial College of Science, Technology and Medicine, London, UK.

Received: 6 October 2020 Accepted: 26 December 2020 Published online: 07 January 2021

\section{References}

1. Whiteley L, Padmanabhan S, Hole D, Isles C. Should diabetes be considered a coronary heart disease risk equivalent?: results from 25 years of follow-up in the Renfrew and Paisley survey. Diabetes Care. 2005;28(7):1588-93.

2. Juutilainen A, Lehto S, Ronnemaa T, Pyorala K, Laakso M. Type 2 diabetes as a "coronary heart disease equivalent": an 18-year prospective population-based study in Finnish subjects. Diabetes Care. 2005;28(12):2901-7.

3. Morrish NJ, Wang SL, Stevens LK, Fuller JH, Keen H. Mortality and causes of death in the $\mathrm{WHO}$ multinational study of vascular disease in diabetes. Diabetologia. 2001;44(Suppl 2):S14-21.

4. Abdul-Ghani MA, Tripathy D, DeFronzo RA. Contributions of beta-cell dysfunction and insulin resistance to the pathogenesis of impaired glucose tolerance and impaired fasting glucose. Diabetes Care. 2006;29(5):1130-9.

5. Gastaldelli A, Ferrannini E, Miyazaki Y, Matsuda M, Deronzo RA, San Antonio metabolism s. Beta-cell dysfunction and glucose intolerance: results from the San Antonio metabolism (SAM) study. Diabetologia. 2004;47(1):31-9.

6. Amano T, Matsubara T, Uetani T, Nanki M, Marui N, Kato M, et al. Abnorma glucose regulation is associated with lipid-rich coronary plaque: relationship to insulin resistance. JACC Cardiovas imaging. 2008;1(1):39-45.

7. Iguchi T, Hasegawa T, Otsuka K, Matsumoto K, Yamazaki T, Nishimura S, et al. Insulin resistance is associated with coronary plaque vulnerability: insight from optical coherence tomography analysis. Eur Heart J Cardiovasc Imaging. 2014;15(3):284-91.

8. Robins SJ, Rubins HB, Faas FH, Schaefer EJ, Elam MB, Anderson JW, et al. Insulin resistance and cardiovascular events with low HDL cholesterol: the Veterans Affairs HDL Intervention Trial (VA-HIT). Diabetes Care. 2003;26(5):1513-7.

9. Stone GW, Maehara A, Lansky AJ, de Bruyne B, Cristea E, Mintz GS, et al. A prospective natural-history study of coronary atherosclerosis. N Eng J Med. 2011;364(3):226-35.

10. Matthews DR, Hosker JP, Rudenski AS, Naylor BA, Treacher DF, Turner RC. Homeostasis model assessment: insulin resistance and beta-cell function from fasting plasma glucose and insulin concentrations in man. Diabetologia. 1985;28(7):412-9.

11. McLaughlin T, Abbasi F, Cheal K, Chu J, Lamendola C, Reaven G. Use of metabolic markers to identify overweight individuals who are insulin resistant. Ann Intern Med. 2003;139(10):802-9.

12. Rutter MK, Meigs JB, Sullivan LM, D'Agostino RB Sr, Wilson PW. Insulin resistance, the metabolic syndrome, and incident cardiovascular events in the Framingham Offspring Study. Diabetes. 2005;54(11):3252-7.

13. Diethrich EB, Pauliina Margolis M, Reid DB, Burke A, Ramaiah $V$, RodriguezLopez JA, et al. Virtual histology intravascular ultrasound assessment of carotid artery disease: the Carotid Artery Plaque Virtual Histology Evaluation (CAPITAL) study. J Endovasc Ther. 2007;14(5):676-86.

14. Nair A, Margolis MP, Kuban BD, Vince DG. Automated coronary plaque characterisation with intravascular ultrasound backscatter: ex vivo validation. Eurolntervention. 2007;3(1):113-20.

15. Bourantas CV, Garcia-Garcia HM, Farooq V, Maehara A, Xu K, Genereux P, et al. Clinical and angiographic characteristics of patients likely to have vulnerable plaques: analysis from the PROSPECT study. JACC CardiovasC Imaging. 2013;6(12):1263-72.

16. Farhan S, Redfors B, Maehara A, McAndrew T, Ben-Yehuda O, De Bruyne B, et al. Impact of pre-diabetes on coronary plaque composition and clinical outcome in patients with acute coronary syndromes: an analysis from the PROSPECT Study. JACC CardiovasC Imaging. 2019;12(4):733-41.

17. Abi Khalil C, Roussel R, Mohammedi K, Danchin N, Marre M. Cause-specific mortality in diabetes: recent changes in trend mortality. Eur J Prev Cardiol. 2012;19(3):374-81.

18. Tabak AG, Herder C, Rathmann W, Brunner EJ, Kivimaki M. Prediabetes: a high-risk state for diabetes development. Lancet. 2012;379(9833):2279-90.

19. Nemoto T, Minami Y, Yamaoka-Tojo M, Kato A, Katsura A, Sato T, et al. Endothelial glycocalyx and severity and vulnerability of coronary plaque in patients with coronary artery disease. Atherosclerosis. 2020;302:1-7.

20. Virdis A, Santini F, Colucci R, Duranti E, Salvetti G, Rugani I, et al. Vascular generation of tumor necrosis factor-alpha reduces nitric oxide availability in small arteries from visceral fat of obese patients. J Am Coll Cardiol. 2011;58(3):238-47.

21. Marfella R, Sasso FC, Siniscalchi M, Paolisso P, Rizzo MR, Ferraro F, et al. Peri-procedural tight glycemic control during early percutaneous coronary intervention is associated with a lower rate of in-stent restenosis in patients with acute ST-elevation myocardial infarction. J Clin Endocrinol Metab. 2012;97(8):2862-71.

22. Okada K, Hibi K, Honda Y, Fitzgerald PJ, Tamura K, Kimura K. Association between abdominal fat distribution and coronary plaque instability in patients with acute coronary syndrome. Nutr Metab Cardiovasc Dis. 2020;30(7):1169-78.

23. Kelly CR, Weisz G, Maehara A, Mintz GS, Mehran R, Lansky AJ, et al. Relation of C-reactive protein levels to instability of untreated vulnerable coronary plaques (from the PROSPECT Study). Am J Cardiol. 2014;114(3):376-83.

24. Coutinho M, Gerstein HC, Wang Y, Yusuf S. The relationship between glucose and incident cardiovascular events. A metaregression analysis of published data from 2.0 studies of 95,783 individuals followed for 124 years. Diabetes care. 1999;22(2):233-40. 
25. Plomgaard P, Bouzakri K, Krogh-Madsen R, Mittendorfer B, Zierath JR, Pedersen BK. Tumor necrosis factor-alpha induces skeletal muscle insulin resistance in healthy human subjects via inhibition of Akt substrate 160 phosphorylation. Diabetes. 2005;54(10):2939-45.

26. Caselli C, Del Turco S, Ragusa R, Lorenzoni V, De Graaf M, Basta G, et al. Association of PCSK9 plasma levels with metabolic patterns and coronary atherosclerosis in patients with stable angina. Cardiovasc Diabetol. 2019;18(1):144.

27. Tanaka T, Kishi S, Ninomiya K, Ishizawa T, Kikushima H, Tomii D, et al. Clinical predictors of coronary artery plaque progression by quantitative serial assessment using 320-row computed tomography coronary angiography in asymptomatic patients with type 2 diabetes mellitus. J Cardiol. 2020;76(4):378-84.

28. Despres JP, Lamarche B, Mauriege P, Cantin B, Dagenais GR, Moorjani S, et al. Hyperinsulinemia as an independent risk factor for ischemic heart disease. N Engl J Med. 1996;334(15):952-7.

29. Howard G, O'Leary DH, Zaccaro D, Haffner S, Rewers M, Hamman R, et al. Insulin sensitivity and atherosclerosis. The Insulin Resistance Atherosclerosis Study (IRAS) Investigators. Circulation. 1996;93(10):1809-17.

30. Fontbonne AM, Eschwege EM. Insulin and cardiovascular disease. Paris Prospect Study Diabetes Care. 1991;14(6):461-9.

31. Sasso FC, Pafundi PC, Marfella R, Calabro P, Piscione F, Furbatto F, et al. Adiponectin and insulin resistance are related to restenosis and overall new PCl in subjects with normal glucose tolerance: the prospective AIRE Study. Cardiovasc Diabetol. 2019;18(1):24.

32. Sheng Z, Zhou P, Liu C, Li J, Chen R, Zhou J, et al. Relationships of coronary culprit-plaque characteristics with duration of diabetes mellitus in acute myocardial infarction: an intravascular optical coherence tomography study. Cardiovasc Diabetol. 2019;18(1):136

33. Mitsuhashi T, Hibi K, Kosuge M, Morita S, Komura N, Kusama I, et al. Relation between hyperinsulinemia and nonculprit plaque characteristics in nondiabetic patients with acute coronary syndromes. JACC Cardiovasc Imag. 2011:4(4):392-401.

34. Pu J, Mintz GS, Biro S, Lee JB, Sum ST, Madden SP, et al. Insights into echoattenuated plaques, echolucent plaques, and plaques with spotty calcification: novel findings from comparisons among intravascular ultrasound, near-infrared spectroscopy, and pathological histology in 2,294 human coronary artery segments. J Am Coll Cardiol. 2014;63(21):2220-33.

35. Burchfiel CM, Reed DM, Marcus EB, Strong JP, Hayashi T. Association of diabetes mellitus with coronary atherosclerosis and myocardial lesions. An autopsy study from the Honolulu Heart Program. Am J Epidemiol. 1993;137(12):1328-40.

36. Cariou B, Bonnevie L, Mayaudon H, Dupuy O, Ceccaldi B, Bauduceau B. Angiographic characteristics of coronary artery disease in diabetic patients compared with matched non-diabetic subjects. Diabetes Nutr Metab. 2000;13(3):134-41.

37. Gast KB, Tjeerdema N, Stijnen T, Smit JW, Dekkers OM. Insulin resistance and risk of incident cardiovascular events in adults without diabetes: meta-analysis. PLoS ONE. 2012;7(12):e52036.

38. Lindsey JB, House JA, Kennedy KF, Marso SP. Diabetes duration is associated with increased thin-cap fibroatheroma detected by intravascular ultrasound with virtual histology. Circ Cardiovasc Interv. 2009;2(6):543-8.

39. Wannamethee SG, Shaper AG, Whincup PH, Lennon L, Sattar N. Impact of diabetes on cardiovascular disease risk and all-cause mortality in older men: influence of age at onset, diabetes duration, and established and novel risk factors. Arch Intern Med. 2011;171(5):404-10.

40. Sardu C, Paolisso P, Sacra C, Mauro C, Minicucci F, Portoghese M, et al. Effects of metformin therapy on coronary endothelial dysfunction in patients with prediabetes with stable angina and nonobstructive coronary artery stenosis: the CODYCE Multicenter Prospective Study. Diabetes Care. 2019;42(10):1946-55.

41. Knowler WC, Barrett-Connor E, Fowler SE, Hamman RF, Lachin JM, Walker EA, et al. Reduction in the incidence of type 2 diabetes with lifestyle intervention or metformin. N England J Med. 2002;346(6):393-403.

42. Trifunovic D, Stankovic S, Sobic-Saranovic D, Marinkovic J, Petrovic M, Orlic D, et al. Acute insulin resistance in ST-segment elevation myocardial infarction in non-diabetic patients is associated with incomplete myocardial reperfusion and impaired coronary microcirculatory function. Cardiovasc Diabetol. 2014;13:73

43. Moura FA, Carvalho LS, Cintra RM, Martins NV, Figueiredo VN, Silva QJC, et al. Validation of surrogate indexes of insulin sensitivity in acute phase of myocardial infarction based on euglycemic-hyperinsulinemic clamp. Am J Physiol Endocrinol Metab. 2014;306(4):E399-403.

44. Nishio K, Shigemitsu M, Kusuyama T, Fukui T, Kawamura K, Itoh S, et al. Insulin resistance in nondiabetic patients with acute myocardial infarction. Cardiovasc Revasc Med. 2006;7(2):54-60.

45. Wallander M, Malmberg K, Norhammar A, Ryden L, Tenerz A. Oral glucose tolerance test: a reliable tool for early detection of glucose abnormalities in patients with acute myocardial infarction in clinical practice: a report on repeated oral glucose tolerance tests from the GAMI study. Diabetes Care. 2008;31(1):36-8.

\section{Publisher's Note}

Springer Nature remains neutral with regard to jurisdictional claims in published maps and institutional affiliations.
Ready to submit your research? Choose BMC and benefit from:

- fast, convenient online submission

- thorough peer review by experienced researchers in your field

- rapid publication on acceptance

- support for research data, including large and complex data types

- gold Open Access which fosters wider collaboration and increased citations

- maximum visibility for your research: over $100 \mathrm{M}$ website views per year

At BMC, research is always in progress.

Learn more biomedcentral.com/submissions 